\title{
ESTIMATION OF ENTRANCE SURFACE RADIATION DOSE TO THYROID REGION IN COMPUTED TOMOGRAPHY BRAIN EXAMINATION
}

\author{
VISAKH T, SURESH SUKUMAR*, ABHIMANYU PRADHAN
}

Department of Medical Imaging Technology, School of Allied Health Sciences, Manipal Academy of Higher Education, Manipal, Karnataka, India. Email: suresh.sugumar@manipal.edu

Received: 04 August 2018, Revised and Accepted: 05 September 2018

\section{ABSTRACT}

Objective: The objective of this study was to estimate the entrance surface radiation dose to the thyroid region in a computed tomography (CT) brain scan.

Methods: Unfors Multi-O-Meter equipment was used to measure the entrance surface at the thyroid region of adult patients ranging from 18 to 70 years of age. A total of 115 patients were included in the study based on convenience sampling. The Multi-O-Meter was kept at the thyroid region during the scan, and the values for entrance surface dose (ESD) were noted from its monitor after the scan was complete.

Results: The obtained data were analyzed and violate normal distribution; therefore, the median and quartiles were computed. The overall median (Q1, Q2), ESD of the patients, was 1.335 (1.213, 1.529) mGy. The minimum and maximum dose values recorded were 1.015 mGy and 1.964 mGy, respectively.

Conclusions: The result showed a significant amount of entrance surface radiation dose to the thyroid region while taking a brain scan. This data can be used for optimization of radiation protection while undergoing CT scans of brain to reduce exposure to thyroid region.

Keywords: Entrance surface dose, Computed tomography, Thyroid, Computed tomography brain.

(C) 2019 The Authors. Published by Innovare Academic Sciences Pvt Ltd. This is an open access article under the CC BY license (http://creativecommons. org/licenses/by/4. 0/) DOI: http://dx.doi.org/10.22159/ajpcr.2019.v12i1.28932

\section{INTRODUCTION}

Computed tomography (CT) is the first medical imaging modality made possible by the computer to visualize the inner sections of body parts, overcomes the problem of overlapping structures, but higher cost, prolonged exposure time, and high radiation exposure being the main drawbacks of it $[1,2]$. Exposure to ionizing radiation produces several harmful effects in the body. The biological effects of radiation vary according to tissues. Tissue weighting factor $\left(\mathrm{W}_{\mathrm{T}}\right)$ is the one that gives the relative risk associated with irradiation. $\mathrm{W}_{\mathrm{T}}$ is important because whole body uniform irradiation occurs rarely, and the absorbed dose received and sensitivity to radiation-induced responses varies for each tissue [3].

The thyroid is a ductless and large gland in the neck region [4]. It is anteriorly situated, entrance radiation dose received by them is considerably high. Thyroid is an intermediate sensitive organ; therefore, the exposure to radiation can increase the risk of cancer. Thyroid cancer is the most frequent endocrine cancer and one of the most distressing diseases $[5,6]$. The estimated radiation dose to thyroid in Chernobyl accident showed a mean value of approximately $0.2 \mathrm{mGy}$ in thyroid cancer cases [7]. In the USA, the incidence of thyroid cancer increased from 3.6/100,000 in 1973 to 8.7/100,000 in 2002. The value increased to nearly 2.4 times [8]. In China, there was an increase in the incident of thyroid cancer by $14.51 \%$ from 2003 to 2007 [9]. Internationally, there was an increase of $48 \%$ in males and $66.7 \%$ in females [8]. Since cancer risk from radiation does not have a definite threshold, measuring the dose received is the key to assess its risk [7]. Measuring the doses can help in limiting and optimizing the radiation. Entrance surface dose (ESD) is a quantity that measures the amount of radiation received by the patient from a diagnostic imaging procedure [3].

Standards for measuring and limiting the exposure were developed after the knowledge of harmful effects produced by ionizing radiation [3]. ESD is the measure of radiation dose absorbed by skin where the X-ray beam enters the patient. ESD can be measured directly with a thermoluminescent dosimeter (TLD) or computed from measurements made with an ionization chamber. During CT scan, a major part of the radiation dose is received by the area exposed to the primary beam. The volume of tissue lying outside the region of interest also gets exposed from secondary radiation [10]. Hence, it is essential to estimate the dose received by the thyroid gland during CT brain examinations. The occurrence of radiation-induced cancer is a major concern nowadays. Since radiation-induced cancers do not have a known threshold, we need to keep the dose delivered as low as possible. To optimize the radiation protection, we need to measure the dose received. This study estimates the ESD to thyroid region during a CT brain examination using Multi-O-Meter.

\section{METHODS}

The study approval was attained from the Institutional Research Committee, School of Allied Health Sciences and Ethics Committee, Kasturba Hospital, Manipal. The study was registered in CTRI and was allotted the registration number, CTRI/2017/05/008682. The study was an observational descriptive study, conducted in the Radiodiagnosis and Imaging Department at Kasturba Hospital, Manipal, during April 2017-March 2018. The sample size was obtained using the formula for the estimation of mean. The sample included in the study was 115 males and females referred for CT brain examination. Informed consents were obtained from all the study participants. Subjects with age ranging from 17 to 70 years were included in the study. Individual with a history of trauma and uncooperative patients was excluded from this study.

115 subjects had undergone CT in 64 slice Brilliance MDCT Philips CT scanner using routine parameters. The patient was positioned as for the routine brain scan and the Multi-O-Meter was kept at the level of C5-T1 in the anterior part of the neck to measure the ESD to the thyroid gland. The values were obtained in mGy. The data were analyzed using Social Package of Statistical Science software (SPSS, version 20.0) and results were obtained. 


\section{RESULTS}

\section{Descriptive statistics}

A total of 115 subjects referred for CT brain were included in this study with age ranging from 18 to 70 years. It was observed that the mean age of the participants as 43.03 with SD 13.52. Among the 115 study participants, $72(63 \%)$ were male and $43(37 \%)$ were female.

\section{Result of the objective}

We have estimated/reported the median and upper and lower quartiles of the entrance surface radiation dose (ESD) as data violate the normality assumption. The median ESD of the patients was 1.335 $\mathrm{mGy}\left(\mathrm{Q}_{1}=1.213, \mathrm{Q}_{3}=1.529\right)$. The minimum and maximum ESD values recorded were $1.015 \mathrm{mGy}$ and $1.964 \mathrm{mGy}$, respectively (Table 1).

\section{DISCUSSION}

The present study estimates the ESD to the thyroid region during the CT brain examination using routine protocol. A Multi-O-Meter was used to measure the ESD to the thyroid region which was placed at the level of thyroid in the neck. The estimated median ESD of the thyroid region was 1.335 mGy during CT brain scan. The epidemiological studies done on Chernobyl accident survivors showed that for inducing thyroid cancer risk, a dose of $0.2 \mathrm{~Gy}$ is required [7]. The result of our study shows a much lesser value when compared to the dose required to induce thyroid cancer. Even though they have measured the effective dose and the present study measures ESD, the dose value is substantially low. Even if a patient undergoes the study multiple times, it is less likely to reach this value. In the present study, ESD is not converted to effective dose because the phantom study was not done. Further studies can be done using phantom to evaluate the effective dose to the thyroid region.

However, CT brain is a common examination done for the screening of brain in case of brain pathologies and brain evaluation in trauma cases. It could, therefore, contribute to collective dose in a person's lifespan. A patient may get irradiated from not only from diagnostic imaging but also from natural background radiation, occupational radiation, and therapeutic procedures. This will lead to an increase in the cumulative dose. Radiation-induced cancer does not have a fixed threshold or a minimum value below which there are no chances of developing the disease. As there is no safe dose level, the radiation dose from diagnostic imaging should be kept as low as possible. Even though the present study estimated a value of $1.335 \mathrm{mGy}$, it can be further reduced with optimization techniques. ESD to the thyroid can be reduced significantly with the use of thyroid shield. In a study conducted by Ribeiro et al. [11], they evaluated the use of thyroid shield in protecting the thyroid gland from scattered radiation during mammography procedure and found that there was a reduction of $89 \%$ on the ESD of the thyroid with protection. The ESD to the thyroid gland during mammography without thyroid shield and with thyroid shield was 0.16 $\mathrm{mGy}$ and $0.018 \mathrm{mGy}$, respectively. This shows that a major decrease in the dose can be achieved by the use of thyroid shield. A similar study was done by Beaconsfield et al. [12], wherein they got a mean dose value over the surface of the thyroid gland in CT head scan with and without the use of thyroid shield. The mean ESD measured at the surface of the thyroid was $1.56 \pm 0.31$ mGy without thyroid protection which was quite similar to the result of the present study. The slight increase of ESD values in their study could be due to the use of $300 \mathrm{~mA}$ for the scan while the present study employed automatic exposure control. They used TLD to measure the scattered radiation, whereas in this study we used Multi-O-Meter. They also measured ESD to thyroid with the use of thyroid shield and observed $45 \%$ reduction in radiation dose with thyroid protection.

Table 1: Summary statistics of ESD

\begin{tabular}{lllll}
\hline Variable & $\begin{array}{l}\text { Number of } \\
\text { participants }\end{array}$ & $\begin{array}{l}\text { Median } \\
(\mathbf{Q 1}, \mathbf{Q 3})(\mathrm{mGy})\end{array}$ & $\begin{array}{l}\text { Min. } \\
\text { (mGy) }\end{array}$ & $\begin{array}{l}\text { Max. } \\
\text { (mGy) }\end{array}$ \\
\hline ESD & 115 & $1.335(1.213,1.529)$ & 1.015 & 1.964 \\
\hline
\end{tabular}

In the present study, we observed that as scan length varies ESD values also vary. However, in some cases, different ESD values were obtained with the same length. This could be due to the relative position of thyroid whether it is close or far from the area covered scanning. More scattered radiation is likely to reach the thyroid gland from the base of the skull. Hence, if the area coverage includes more toward the lower part, the ESD increases and if the area covered is more on the upper part ESD decreases. In the study conducted by Su et al. [9], the thyroid doses were estimated to be 1.10-2.45 mGy for CT head scan. This variation in the ESD values could be because of the fact that the result was derived from pediatric patients who underwent CT head scans. Size of the neck is smaller in pediatric patients and due to this reason, the thyroid is located closer to the base of the skull. As a result, more scattered radiation reaches thyroid when the patient undergoes the scan. The present study was conducted among adult patients within the age group of $18-80$ years.

There are several methods to derive ESD. Mortazavi et al. [13] used TLD100, HARSHAW to measure the entrance skin dose, whereas another author Al Senan et al. [14] used a device called MicroStar ${ }^{\mathrm{TM}}$ to read the values recorded by the optically stimulated luminescence dosimeter. In our present, we used Multi-0-Meter to measure the entrance skin dose.

Since the thyroid is a radiosensitive organ, measures should be taken to reduce the dose in all ways possible. Even though the dose received from one scan may not be high enough to cause any biological effect, the cumulative dose received by the patient can lead to consequences in the future. It increases the cancer risks of the thyroid. The use of thyroid shield and proper area coverage is a way to provide better protection to the thyroid gland.

\section{CONCLUSION}

The result showed that median ESD was 1.33 mGy of entrance surface radiation dose to the thyroid region while taking a brain scan. We can, therefore, use radiation protection techniques such as covering the thyroid region with a thyroid shield during the scan to reduce unnecessary exposure.

Hence, this data can be used for optimization of radiation exposure to the thyroid region using protective shielding while undergoing CT brain examination.

\section{ACKNOWLEDGMENT}

We would like to thank the Department of Radiodiagnosis and Imaging, Kasturba Hospital, Manipal, for allowing us to collect data for the thesis.

\section{AUTHORS' CONTRIBUTIONS}

Visakh T: Design, Literature search, Data Acquisition, Data Analysis, Manuscript Preparation, and Editing. Suresh Sukumar: Concept, Design Literature search, Data Acquisition, Data Analysis, Statistical Analysis, Manuscript Editing, and review. Abhimanyu Pradhan: Concept, Design, Literature search, Data Analysis, Statistical Analysis, Manuscript Editing, and review.

\section{CONFLICTS OF INTEREST}

There are no conflicts of interest

\section{REFERENCES}

1. Bushberg JT, Seibert JA, Leidholdt EM, Boone JM. The Essential Physics of Medical Imaging. $3^{\text {rd }}$ ed. Philadelphia, PA: Wolters Kluwer Health/Lippincott Williams and Wilkins; 2012.

2. Bianchi J, Goggins W, Rudolph M. In vivo, thyroid and lens surface exposure with spiral and conventional computed tomography in dental implant radiography. Oral Surg Oral Med Oral Pathol 2000;90:249-53.

3. Sherer MA, Visconti P, Ritenour ER, Haynes K. Radiation Protection in Medical Radiography. $6^{\text {th }}$ ed. Philadelphia, PA: Elsevier-Health Sciences Division; 2010 
4. Nour AH, Khan M, Sulaiman AZ, Batool T, Nour AH, Khan MM, et al. In vitro anti-acetyl cholinesterase and antioxidant activity of selected Malaysian plants. Asian J Pharm Clin Res 2014;7:93-7.

5. Gupta M, Dahiya J, Marwaha RK, Dureja H. Therapies in cancer treatment: An overview. Int J Pharm Pharm Sci 2014;7:1-9.

6. Guo-Qing H, Ying L, Di-Fei C, Yu G, Dan S, Jin-Hai Z, et al. Advances in tumor markers for the early diagnosis of papillary thyroid carcinoma. Int J Pharm Pharm Sci 2016;8:47-51

7. Hall EJ. Radiation biology. Cancer 1985;55:2051-7.

8. Kilfoy BA, Zheng T, Holford TR, Han X, Ward MH, Sjodin A, et al. International patterns and trends in thyroid cancer incidence, 19732002. Cancer Causes Control 2009;20:525-31.

9. Su YP, Niu HW, Chen JB, Fu YH, Xiao GB, Sun QF. Radiation dose in the thyroid and the thyroid cancer risk attributable to CT scans for pediatric patients in one general hospital of China. Int J Environ Res Public Health 2014;11:2793-803.
10. Parry RA, Glaze SA, Archer BR. The AAPM/RSNA physics tutorial for residents. Radiographics 1999;19:1289-302.

11. Ribeiro LP, Entradas DC, Abrantes AF, Rodrigues SI, Reis MV. Evaluation of use of thyroid shield in mammography: A preliminary study. Int J Radiol Radiat Ther 2017;3:2-4

12. Beaconsfield T, Nicholson R, Thornton A, Al-Kutoubi A. Would thyroid and breast shielding be beneficial in $\mathrm{CT}$ of the head. Eur Radiol 1998;8:664-7

13. Mortazavi SM, Ghiassi-Nejad M, Bakhsi M, Jafari-Zadeh M, Kavousi A, Ahmadi J, et al. Entrance surface dose measurement on the thyroid gland in orthopantomography: The need for optimization. Iran J Radiat Res 2004;2:21-6.

14. Al Senan R, Mueller DL, Hatab MR. Estimating thyroid dose in pediatric CT exams from surface dose measurement. Phys Med Biol 2012;57:4211-21. 